\title{
EVALUATION OF FUEL PELLETS AS SECONDARY PRODUCT WHEN PRESSING OIL FROM GRAPEVINE SEEDS
}

\author{
Vladimir Masan $^{1}$, Patrik Burg ${ }^{1}$, Vladimir Visacki ${ }^{2}$, Ponjican Ondrej ${ }^{2}$ \\ ${ }^{1}$ Mendel University in Brno, Czech Republic; ${ }^{2}$ University of Novi Sad, Serbia \\ vladimir.masan@mendelu.cz, vladimir.visacki@polj.uns.ac.rs
}

\begin{abstract}
In recent years, there is growing importance of a new non-waste technology in wine industry that contributes to environmental protection. Relatively frequently vineyard waste wood cut off during winter time is used to produce fuel pellets. Another option is the use of grape marc for the briquettes production and then for further production of energy or gaining oil by pressing the separated seeds. This paper discusses the evaluation of pellets features from cakes of grape seeds from the energetical point of view as well as from the point of compliance with the standards for production of pellets. The calorimetric measurement was first determined by the calorific value of the pellets of grapevines wood, seeds, grape marc and cakes. The pellets of the separated seeds had the net calorific value of $19.54 \pm 0.67 \mathrm{MJ} \cdot \mathrm{kg}^{-1}$ compared to those from grapevine wood pellets $16.39 \pm 0.18 \mathrm{MJ} \cdot \mathrm{kg}^{-1}$, seedless grape marc pellets $16.85 \pm 0.46 \mathrm{MJ} \cdot \mathrm{kg}^{-1}$ and cake pellets $18.60 \pm 0.72 \mathrm{MJ} \cdot \mathrm{kg}^{-1}$. The smaller net calorific value of cake pellets compared with the pellets made from seeds is due to the reduced amount of oil-based substances in cake produced during the oil-pressing process. The quantity is reduced by $40-$ $60 \%$, yet the calorific value is satisfactory, when compared to other types of fuel. When carrying out the pellet test, emissions were analysed and in most parameters complied with national as well as international standards. Double amount of sulphur content has been found in cake pellets, which has negative effects on the environment. The content of chlorine was slightly higher, around $0.11 \%$ compared to the limit of $0.1 \%$, which negatively affects the combustion equipment. A possible solution to reduce these over-limit values is to mix pellets from cake with other pellets. The mixture that meets all emission requirements and reaches a calorific value of $17.36 \pm 0.06 \mathrm{MJ} \cdot \mathrm{kg}^{-1}$ was tested and is finally made up of $50 \%$ of seedless grape marc, $30 \%$ of grapevine waste wood and $20 \%$ of cake.
\end{abstract}

Keywords: pellets, calorific value, grape marc, wood, grape seeds.

\section{Introduction}

Bilandzija et al. [1] state that the use of biomass energy has got an increasing importance in ensuring renewable energy sources, in enhancing energy self-sufficiency in the regions, in reducing greenhouse gas emissions, in maintaining cultural landscapes by bigger use of biomass waste, in creating of new jobs and in stabilizing the rural area. The use of biomass can significantly contribute to the diversification of resources more evenly dispersed in a particular area and thereby ensure greater stability in energy supply [2]. On the other hand, Hamelinck et al. [3] argue that due to the large amount of phytomass energy needed for obtaining the energy equivalents (compared to, for example, coal) it is not suitable for long distance transport.

In recent years, there is a growing importance of new non-waste technology in wine industry that contributes to environmental protection [4]. Relatively frequent is use of vineyard waste wood cut-offs during winter time that are used to produce fuel pellets [5]. Another option is the use of grape marc for the briquettes production (and then for further production of energy) or gaining oil by pressing the separated seeds.

When using biomass for energy purposes, it is usually necessary to make the adjustments accordingly. This is based on the character, most often it is either crushing or chipping, or on the use of the further disintegration process and subsequent application of the resulting mass in the production of pellets [6-8]. Another burden is drying of the input raw material [9].

When evaluating the use of grape seed cakes from pressing of the grape seeds, it is necessary to consider the great advantage of such pellets, which require minimal post-treatment. The resulting cakes are pellet-like and moisture-minimized. The content of this non-lubricated oil may also have a higher calorific value.

According to the findings of Vitázek et al. [10], it is necessary to evaluate the new biofuel not only from the energy point of view, but also regarding the fulfilling of the standards accordingly to the qualitative characteristics, as well as to the content of the limit elements. It is important to use these raw materials in the production of pellets to evaluate them as regards the composition of ash and flue gas emissions. 
The objective of this work was to compare the grape seed cakes made from the production of oil by pressing the grape seeds and pellets from the waste material from the vinicultural and wine production from the point of calorific value and fulfilling the specific parameters according to the international standards.

\section{Materials and methods}

For the purpose of this experiment there were five samples of single-component pellets produced and one sample of a multi-component pellet, Table 1.

Biomass feedstock information to produce pellets

Table 1

\begin{tabular}{|c|c|c|}
\hline $\begin{array}{c}\text { Tested samples } \\
\text { of pellets }\end{array}$ & Used materials & $\begin{array}{c}\text { Description / producing } \\
\text { process }\end{array}$ \\
\hline 1 & Grape marc & $\begin{array}{c}\text { Solid remains of grapes after } \\
\text { pressing for juice }\end{array}$ \\
\hline 2 & Seedless grape marc & $\begin{array}{c}\text { Grape marc after separating the } \\
\text { seeds }\end{array}$ \\
\hline 3 & Separated grape seeds & $\begin{array}{c}\text { Separated seeds from the grape } \\
\text { marc }\end{array}$ \\
\hline 4 & Grapevines waste wood & $\begin{array}{c}\text { Wood after the winter cut of } \\
\text { vineyards }\end{array}$ \\
\hline 5 & Grape seed cakes & $\begin{array}{c}\text { Product remains of grape seeds } \\
\text { after pressing for oil }\end{array}$ \\
\hline 6 & $\begin{array}{c}\text { Mix: } 50 \% \text { seedless grape marc pellets, } \\
30 \% \text { waste wood pellets, } 20 \% \text { cake pellets }\end{array}$ & $\begin{array}{c}\text { Single-component pellets } \\
\text { mixed together }\end{array}$ \\
\hline
\end{tabular}

The production of pellet samples 1-4 was realised on a commercial pelletizing line MGL 400 (KovoNovak, made in the Czech Republic). Sample 5 was produced on a small capacity oil screw press UNO (Farmet, made in Czech Republic). Sample number 6 is a mixed sample of pellets 3, 4 and 5. All samples were produced in three repeats.

The energy value of the pellets, samples $1-6$, was verified by a set of calorimetric measurements in order to determine the gross calorific value $(\mathrm{GCV})$ and net calorific value (NCV). For determination of the calorific value, the calorimeter Parr 6400 (Parr Instrument, USA) was used. Determination of the GCV for solid biofuels was carried out according to the standard ISO 18125:2017. The obtained GCV was calculated to the NCV according to the formula 1.

$$
Q^{r}{ }_{i}=Q^{r}{ }_{s}-\gamma \cdot\left(W_{t}^{r}+8.94 . H_{t}^{r}\right),
$$

where $Q^{r}{ }_{i}-\mathrm{NCV}$ of the evaluated sample, $\mathrm{MJ} \cdot \mathrm{kg}^{-1}$;

$Q^{r}{ }_{s}-\mathrm{GCV}$ of the original sample, $\mathrm{MJ} \cdot \mathrm{kg}^{-1}$;

$\gamma$ - ratio of evaporation of $1 \% \mathrm{H}_{2} \mathrm{O}, \mathrm{MJ} \cdot \mathrm{kg}^{-1}$, at temperature $25^{\circ} \mathrm{C}, \gamma=0.02442 \mathrm{MJ} \cdot \mathrm{kg}^{-1}$;

8,94 - hydrogen to water conversion ratio of, - ;

$W_{t}^{r}$ - total water content in the original sample, \%;

$H^{r}{ }_{t}$ - total hydrogen content in the original sample, $\%$.

The weight of the samples was measured by the analytical scales KERN AES 200-4C (Kern \& Sohn, Germany) with $0.0001 \mathrm{~g}$ resolution.

The analysis of the elementary composition was provided through the TOC/TN analyser multi N/C 2100S (Analytik Jena, Germany) and the gas chromatograph Trace GC ultra (Thermo Fisher Scientific, USA).

The moisture content of selected biofuels was determined according to the standard ISO 181342:2017 by means of the laboratory oven Memmert UFE 400 (Memmert, Germany). The samples were dried out at the temperature of $105^{\circ} \mathrm{C}$ to a constant weight (formula 2). 


$$
w=\frac{m_{1}-m_{2}}{m_{1}},
$$

where $\mathrm{w}-$ moisture content, \%;

$m_{1}$ - original weight, g;

$m_{2}-$ dry mass weight, $\mathrm{g}$.

The ash content determination in the tested samples was analysed on the muffle furnace BEA 8,2 (BEA, Austria) and calculated by the standard: ISO 18122:2015. The ash content was calculated from the formula 3 .

$$
A=\frac{m_{3}-m_{1}}{m_{2}-m_{1}} \times 100
$$

where $A$ - ash content, \%;

$m_{1}$ - mass of the empty drying container, $\mathrm{g}$;

$m_{2}-$ mass of the dish plus the test sample, $\mathrm{g}$.

$m_{3}-$ mass of the dish plus ash, $\mathrm{g}$.

All measurements were performed in triplicate and the result value was calculated as the average of three measurements with SD. These determined values were evaluated using the analysis of variance (ANOVA) and later on mutually compared by the Tukey's test at the significance level $\alpha=0.05$. A statistical analysis was carried out using the software package Statistica 12.0 (StatSoft Inc., USA).

\section{Results and discussion}

The moisture, NCV and ash content form the basis of the solid fuel technical evaluation in terms of their suitability for energy purposes, Table 2. For the comparison, the regular values of NCV of the fuel pellets made from the wood waste is approximately $16-19 \mathrm{MJ} \cdot \mathrm{kg}^{-1}$, the moisture value is from 7 up to $10 \%$ and the ash content is somewhere between 0.4 and $2 \%$ [11-13].

Table 2

\begin{tabular}{|c|c|c|c|c|c|c|c|c|}
\hline \multirow{2}{*}{$\begin{array}{c}\text { Tested } \\
\text { samples } \\
\text { of pellets }\end{array}$} & \multirow{2}{*}{$\begin{array}{l}\text { Moisture } \\
\text { (wt. \%) }\end{array}$} & $\mathbf{H}$ & $\mathrm{C}$ & $\mathbf{N}$ & $\mathbf{O}$ & \multirow{2}{*}{$\begin{array}{l}\text { Ash } \\
(\%)\end{array}$} & \multirow{2}{*}{$\begin{array}{c}\text { GCV } \\
\left(\mathbf{M J} \cdot \mathbf{k g}^{-1}\right)\end{array}$} & \multirow{2}{*}{$\begin{array}{c}\text { NCV } \\
\left(\mathbf{M J} \cdot \mathbf{k g}^{-1}\right)\end{array}$} \\
\hline & & \multicolumn{4}{|c|}{ (wt. \%) } & & & \\
\hline 1 & 9.63 & 6.02 & 48.31 & 1.63 & 46.42 & 5.12 & 18.58 & $17.03 \pm 0.17^{\mathrm{a}}$ \\
\hline 2 & 9.78 & 3.81 & 51.34 & 0.67 & 39.72 & 4.83 & 17.92 & $16.85 \pm 0.46^{\mathrm{a}}$ \\
\hline 3 & 9.52 & 6.08 & 52.58 & 1.32 & 38.38 & 3.42 & 21.10 & $19.54 \pm 0.67^{\mathrm{c}}$ \\
\hline 4 & 7.33 & 7.47 & 50.21 & 0.47 & 43.92 & 0.62 & 18.20 & $16.39 \pm 0.18^{\mathrm{a}}$ \\
\hline 5 & 7.97 & 9.60 & 53.42 & 2.08 & 40.17 & 3.23 & 20.89 & $18.60 \pm 0.72^{\mathrm{bc}}$ \\
\hline 6 & 8.23 & 4.58 & 51.02 & 1.37 & 41.64 & 1.14 & 18.56 & $17.36 \pm 0.06^{\mathrm{ab}}$ \\
\hline
\end{tabular}

Elementary composition, physical characteristics and calorific values of tested samples

* Legend: Values means \pm standard deviations of triplicate determinations. Means followed by different lowercase letters in the same column indicates significant differences $(P<0.05)$.

Sample 1 represents the most common vinicultural waste product. Unfortunately, for the further use within the bioenergy it needs the drying process. Miranda et al. [14] state that for the washed grape pomace, the average value of GCV is $19.5 \mathrm{MJ} \cdot \mathrm{kg}^{-1}$, at the moisture of $7.49 \%$ and the ash content $7.47 \%$. Verma [13], while using similar materials shows the values accordingly: pellets made of apple juice industrial waste have the value of GCV approximately $20.68 \mathrm{MJ} \cdot \mathrm{kg}^{-1}$, by moisture $12.34 \%$ and ash content $-2.4 \%$; pectin pellets made of citrus shell have the values of GCV $-19.24 \mathrm{MJ} \cdot \mathrm{kg}^{-1}$, by moisture $-13.59 \%$ and ash content $-1.63 \%$; the sunflower husk pellets GCV $-20.27 \mathrm{MJ} \cdot \mathrm{kg}^{-1}$, by moisture $-11.80 \%$ and ash content $-2.78 \%$. Sample 2, of pellets derived from seedless grape marc, was found to have a low calorific value. This sample had the highest moisture values, due to the entry material that was significantly lowered during the pellet production.

The input material had worse quality for pelletizing lines, there was not an ideal interconnecting of pellets and problematic was also higher production of ash during combustion. When comparing to 
sample 1, the lower NCV value is due to the separation of most seeds. To prove this, sample 3 was observed and it has reached the highest NCV. Berndes et al. [6] state that the calorific value of plant raw materials can increase the content of more valuable components, such as resins or oils. However, from the practical application point of view, it is not possible to envisage the use of seeds for energy purposes [15]. Due to its uniqueness, it will find use in the food or cosmetics industry. Sample 4 represents pellets commonly available on the market, which, according to Souček et al. [5], have achieved standard results. Sample 5 reached a lower NCV compared to sample 3 due to the reduction of the oil content by pressing. However, the ash content remained almost identical. All pellets showed acceptable calorific values within the range between 16.39 and $19.54 \mathrm{MJ} \cdot \mathrm{kg}^{-1}$.

Table 3 shows the results corresponding to the analyses of the pellets. These samples usually achieved the parameters. The limits of selected parameters for woody and non-woody pellets are determined by ISO 17225-2 and ISO 17225-6 standards.

Table 3

Reference specifications for pellets and achieved values

\begin{tabular}{|c|c|c|c|c|c|c|c|c|c|}
\hline $\begin{array}{c}\text { Tested } \\
\text { samples of } \\
\text { pellets }\end{array}$ & \multirow{2}{*}{ Used standard } & \multicolumn{2}{|c|}{$\begin{array}{c}\text { Moisture, } \\
\text { wt. \% }\end{array}$} & \multicolumn{2}{|c|}{ Ash, \% } & \multicolumn{2}{|c|}{ S, \% } & \multicolumn{2}{c|}{ Cl, \% } \\
\cline { 3 - 10 } & & MV & LV & MV & LV & MV & LV & MV & LV \\
\hline 1 & ISO 17225-6 & 9.63 & $\leq 12.0$ & 5.12 & $\leq 6.0$ & 0.12 & $\leq 0.20$ & 0.03 & $\leq 0.10$ \\
\hline 2 & ISO 17225-6 & 9.78 & $\leq 12.0$ & 4.83 & $\leq 6.0$ & 0.08 & $\leq 0.20$ & 0.02 & $\leq 0.10$ \\
\hline 3 & ISO 17225-6 & 9.52 & $\leq 12.0$ & 3.42 & $\leq 6.0$ & 0.17 & $\leq 0.20$ & 0.03 & $\leq 0.10$ \\
\hline 4 & ISO 17225-2 & 7.33 & $\leq 10.0$ & 0.62 & $\leq 0.7$ & 0.02 & $\leq 0.04$ & 0.01 & $\leq 0.02$ \\
\hline 5 & ISO 17225-6 & 7.97 & $\leq 12.0$ & 3.23 & $\leq 6.0$ & 0.40 & $\leq 0.20$ & 0.11 & $\leq 0.10$ \\
\hline 6 & ISO 17225-6 & 8.23 & $\leq 12.0$ & 1.14 & $\leq 6.0$ & 0.18 & $\leq 0.20$ & 0.03 & $\leq 0.10$ \\
\hline
\end{tabular}

* Legend: $M V$ - measured value, $L V$ - limited value by standards.

The moisture content of the samples examined was lower than $10 \%$ by weight, so the pellets met the requirements. Double amount of the sulphur content has been found in cake pellets (sample 5), which has negative effects on the environment, Vitázek et al. [10]. The content of chlorine was slightly higher, around $0.11 \%$ compared to the limit of $0.1 \%$, which negatively affects the combustion equipment [16]. A possible solution to reduce these over-limit values is to mix pellets from cake with other pellets. The analysis of pellets, composed by mixtures of biomass residues, is interesting in order to meet the limits of the given standards. The mixture pellet (sample 6) that meets all emission requirements and reaches a calorific value of $17.36 \pm 0.06 \mathrm{MJ} \cdot \mathrm{kg}^{-1}$ was tested and is finally made up of $50 \%$ of de-seeded grape marc, $30 \%$ of grapevines and $20 \%$ of cake.

The analysis of pellets composed by mixtures of biomass residues is interesting in order to obtain a suitable combination with respect to their physical and chemical characteristics.

\section{Conclusions}

1. The results obtained from the analysis of the investigated samples show that the majority of the examined pellets satisfy the standard requirements given for the pellets in the ISO17225-2 and ISO 17225-6.

2. The energetic value of pellets produced from the wine industry waste products was verified by a set of calorimetric measurements, in which there were stated the values of net calorific values. Depending on the nature of the tested samples - grape marc, seedless grape marc, separated grape seeds, grape seed cakes and mixed sample, it ranged between 16.85 and $19.54 \mathrm{MJ} \cdot \mathrm{kg}^{-1}$.

3. The sample similar to the commercial pellets made of grapevines waste wood presented better characteristics than the others, especially in the ash content, chlorine and sulphur percentage. On the contrary, they presented lower values of the net calorific value, but still the values commonly reached the level of $16.39 \mathrm{MJ} \cdot \mathrm{kg}^{-1}$.

4. The mixture samples made from $50 \%$ of seedless grape marc pellets, $30 \%$ of waste wood pellets and $20 \%$ of cake pellets show good thermal characteristics for their use in combustion processes at all standard limits by ISO 17225-6. 


\section{Acknowledgements}

This paper was supported by the project CZ.02.2.67/0.0/0.0/16_016/0002366 Infrastructure for competitive graduate of Mendel University in Brno, this is co-financed from Operational Programme Research, Development and Education.

\section{References}

[1] Bilanzdija N., Voca N., Kricka T., Matin A., Jurisic V. Energy potential of fruit tree pruned biomass in Croatia. Spanish Journal of Agricultural Research, vol. 10, 2012, pp. 292-298.

[2] Bentsen N., Felby C. Biomass for energy in the European Union - a review of bioenergy resource assessments. Biotechnology for Biofuels, vol. 5, 2012, no. 25.

[3] Hamelinck C.N., Suurs R.A.A., Faaij A.P.C. International bioenergy transport costs and energy balance. Biomass Bioenergy, vol. 29, 2005, pp. 114-134.

[4] Boulton R.B., Singleton V.L., Bisson F.L., Kunkee R.E. Principles and practices of winemaking. New York: Springer + Business Media, 2010. 604 p.

[5] Souček J., Burg P. The determination of heating value by wood chips of waste cane. Acta Universitatis Agriculturae et Silviculturae Mendelianae Brunensis, vol. 58, 2010, pp. 185-190.

[6] Berndes. G., Hoogwijk. M., Van Den Broek. R. The contribution of biomass inthe future global energy supply: a review of 17 studies. Biomass Bioenergy, vol. 25, 2003, pp. 1-28.

[7] Maga. J. etc. Komplexný model využitia biomasy na energetické účely (A comprehensive model of using biomass for energy purposes). Nitra: SPU v Nitre, 2008. 183 p. (In Slovak).

[8] Fiori. L., Florio. L. Gasification and Combustion of Grape Marc: Comparison Among Different Scenarios. Waste and Biomass Valorization, vol. 1, 2010, pp. 191-200.

[9] Pastorek. Z., Kára. J., Jevič. P. Biomasa: obnovitelný zdroj energie (Biomass: a renewable energy source). Praha: FCC PUBLIS s.r.o., 2004. 288 p. (In Czech).

[10] Vitázek I., Klúčik J., Mikulová Z., Vereš P. Effects on concentration of selected gaseous emissions at biomass combustion. AIP Conference Proceedings, 2016, vol. 1768. [online] [01.03.2018]. Available at: http://aip.scitation.org/doi/abs/10.1063/1.4963044

[11] Thrän etc. Global Wood Pellet Industry and Trade Study 2017. IEA Bioenergy, 2017. 243 p.

[12] Roy M.M., Dutta A., Corscadden K. An experimental study of combustion and emissions of biomass pellets in a prototype pellet furnace. Applied Energy, vol. 108, 2013, pp. 298-307.

[13] Verma V.K., Bram S., Delattin F. etc. Agro-pellets for domestic heating boilers: Standard laboratory and real life performance. Applied Energy, vol. 90, 2012, pp. 17-23.

[14] Miranda M.T., Arranz J.I., Román S. etc. Characterization of grape pomace and pyrenean oak pellets. Fuel Processing Technology, vol. 92, 2011, pp. 278-283.

[15] Bewley J., Black M., Halmer P. The encyclopedia of seeds: science. technology and uses. 2nd. Cambridge. MA: CABI. XIII, 2006. 828 p.

[16] Wei X., Schnell U., Hein K. Behaviour of gaseous chlorine and alkali metals during biomass thermal utilisation. Fuel, vol. 84, 2005, pp. 841-848.

[17] ISO 18125:2017 standard "Solid biofuels: Determination of calorific value".

[18] ISO 18134-2:2017 standard "Solid biofuels: Determination of moisture content - Oven dry method. Part 2: Total moisture - Simplified method".

[19] ISO 18122:2015 standard "Solid biofuels: Determination of ash content".

[20] ISO 17225-2:2014 standard "Solid biofuels: Fuel specifications and classes. Part 2: Graded wood pellets".

[21] ISO 17225-6:2014 standard "Solid biofuels: Fuel specifications and classes. Part 6: Graded nonwoody pellets". 